\title{
On the life and scientific work of Gino Fano*
}

\section{by Alberto Collino ${ }^{\dagger}$, Alberto Conte ${ }^{\ddagger}$, and Alessandro Verra $\$$}

\section{Gino Fano: A Necessarily Brief Presentation}

It is evident to most mathematicians, though any estimate seems likely impossible, that the name of Gino Fano is among the most cited ones, in contemporary geometry and mathematics, nowadays as well as yesterday.

Furthermore, various fortunate geometric objects bear today his name. That's the case for Fano plane in combinatorics and projective geometry, for Fano varieties in algebraic geometry or for the Fano surface of lines of a cubic hypersurface of a 4-dimensional projective space.

Names, or the number of citations, are however irrelevant with respect to the personality we are dealing with. They play, as it always must be, a secondary role to fully understand a scientific life, the importance of his effective realizations, his heritage.

Fano, during all his life, was a prominent mathematician of his time and a major protagonist of the Italian School of Geometry. He played a crucial role in the evolution of several fields of Geometry and in strengthening the relations between Italy and the

\footnotetext{
* Used by courtesy of the Unione Italiana Matematica (UMI). This paper is the introduction to the 2013 online publication of Gino Fano's selected works, commissioned by UMI. See http://www.bdim.eu/item?id=GM_Fano_P_1. The authors wish to express their gratitude to the ICCM Notices for publishing the paper in this issue.

† Universitá di Torino, Dipartimento di Matematica, via Carlo Alberto 10, 10123 Torino, Italy

E-mail: alberto.collino@unito.it

‡ Universitá di Torino, Dipartimento di Matematica, via Carlo Alberto 10, 10123 Torino, Italy

E-mail: alberto.conte@unito.it

§ Universitá Roma Tre, Dipartimento di Matematica e Fisica, Largo San Leonardo Murialdo 1, 00146 Roma, Italy
}

most relevant mathematical and scientific centers of Europe.

Fano's life developed between 1871 and 1952. From the last decade of XIX century, to the period immediately after second World War, his achievements are concerned with the most important topics in Geometry. A very synthetic vision of all this is what we offer in the next introductory pages.

On the other hand, it cannot be the purpose of the present foreword to analyze, with the necessary ampleness and details, Fano's scientific life, nor his influence in today's Geometry and his vaste scientific heritage. All these aspects cannot be confined, specially in the case we are considering, to a small amount of pages of a short, or longer, introduction.

The only analysis of Fano's contributions to Algebraic Geometry, even restricting it to one of his favorite topics, like for instance the projective classification of all families of Fano threefolds, is far beyond the limits of an introduction.

Even more, the same can be said about a historical analysis of Fano's points of view, interests and contributions in a very wide geometric area, which does not exactly coincide with birational classification of algebraic varieties nor with current algebraic geometry.

Concerning this, the realization of a complete scientific biography of Gino Fano, standing in the very rich field of existing contributions to the study of Italian School of Geometry, appears as a mandatory task whose interest and importance are maximal.

Here our goals are limited ${ }^{1}$ as follows: in the con-

\footnotetext{
${ }^{1}$ As a consequence: no bibliography of papers dedicated to Fano's biography or work is present in this introduction. The citations in the footnotes only reflect immediate personal choices, without a systematic attempt of completeness. We apologize for every omission.
} 
cluding part of this section we outline, as far as possible, the principal directions and the arguments of Fano's scientifc work or, at least, some jewels from his work.

The last two sections are timelines. The first one reports the main events from Fano's life and scientific activity. Some references to main, or mainly related, historical events are included.

The second one is a chronologically ordered list of Fano's publications. Every item from this list is quoted in the text by its year, followed by a number denoting its position in the year's list. Starting from 1890, the year of the first publication due to him², the last reprinted book appeared in $1958^{3}$.

We hope that the contents of these essential chronologies could offer basic informations, or precisions, to any person interested to the work of Gino Fano and his life. However two specially nice and vivid descriptions of Gino Fano, as a man and as a scientist, follow this introduction: a memory written by his son Robert Fano and the obituary written by his friend and colleague Alessandro Terracini ${ }^{4}$

Like for the greatest painters, the works of great mathematicians often configure several periods and themes, according to the variations of the intellectual life of their authors and to historical conditions. The works and the life of Gino Fano are a good example of this general principle.

Two cultural frames strongly contributed to his mathematical education and strongly influenced his scientific personality. To make clear what are these frames, it will be enough to mention two academic cities, where the study of Geometry was flourishing in the last decades of XIX century:

the city of Torino, where the golden age of Italian Algebraic Geometry was approaching its best moments, and the city of Goettingen where Felix Klein was living since $1886^{5}$.

Fano, born in the same day and year of Federigo Enriques (January 51871 ) is definitely associated to this golden age since his very beginning. He came to the University of Torino as a student in 1888, obtaining the degree in Mathematics in 1892 under the direction of Corrado Segre.

He became immediately part of the group of algebraic geometers working in Torino at that time and he

\footnotetext{
2 The translation of Klein's Erlangen Program: see [1890-1].

3 Lezioni di geometria analitica e proiettiva, a famous textbook: see [1940-4].

4 A. Terracini Necrologio di Gino Fano Boll. U.M.I., 7 (1952) 485-490

5 About this interplay cfr. From Turin to Goettingen dialogues and correspondences by E. Luciano and C.S. Roero Boll. storia sci. mat. 32 (2012) 1-232.
}

started in Torino his academic career, being assistant of Enrico D'Ovidio. It is also due to those years the beginning of a very deep scientific interchange, as well as a permanent friendship, with Guido Castelnuovo.

Remarkably, a direct contact with further and very strong perspectives on geometrical studies was made possible to Fano. The reason of this is his visit in the University of Goettingen under the invitation of Felix Klein. Fano spent there about one year, in the period 1893-94. Fano, as Alessandro Terracini writes in the above mentioned memory, had already published in 1890 a translation from German to Italian of Klein's Erlangen Program ${ }^{6}$, following a suggestion of Corrado Segre.

That was the first translation from German of this fundamental paper of Klein. Thus the familiarity with the ideas of Klein, a very fruitful personal interchange with him, as well as Goettingen mathematical atmosphere, gave to the young Fano a further cornerstone, to be connected to the former cornerstone made by his "Italian geometric features", so to build the strong and original personality he was in all the geometric fields, during all his life. Building on such cornerstones, themes and periods of Fano's scientific life evolved in several directions.

The influence of Felix Klein, as well as Fano's relations to German School, are probably reflected by the very high number of his contributions where the general notion of group of geometric transformations takes a central place. This happens in a wide multiplicity of situations.

His expository memory on continuous groups and geometric classification, published in Enziklopaedie der Mathematische Wissenschaft ${ }^{7}$, is a natural example of this fact. It is noteworthy that this contribution of Fano was taken up by Elie Cartan, which around 1914 translated it, writing also some additional parts, for the French edition of Enzyclopaedie ${ }^{8}$.

Fano's contributions to Lie theory, in particular on finite representations of the complex special linear group and the finite generation of its ring of invariant polynomials, are described by Armand Borel in his historical essay on Lie groups ${ }^{9}$. Fano's contributions also appear in the section dedicated to him in the book of Thomas Hawkins on history of Lie groups ${ }^{10}$

\footnotetext{
6 F. Klein Vergleichende Betrachtungen über neuere geometrische Forschungen Verlag von A. Deichert, Erlangen, 1872.

7 See [1907-3] Kontinuierliche geometrische Gruppen; die Gruppentheorie als geometrisches Einteilungsprinzip.

8 E. Cartan Oeuvres complétes volumes I-VI, reprinted by CNRS (1984).

9 A. Borel Essays in the history of Lie groups and algebraic groups, History of Mathematics v. 21, AMS Providence RI (2001).

${ }^{10}$ T. Hawkins The emergence of Lie groups. An essay in history of mathematics (1869-1926) Springer (2000).
} 
It is therefore obvious that the new interplay between geometry and physics, appearing in the late 19th and early 20th centuries, was perfectly clear to him, as well as it is clear his interest on it. This can be appreciated in many ways, for instance from his book on non euclidean geometries, with the explicit subtitle "Geometric introduction to general Relativity" 11 or from conferences and articles due to him.

However physics had to become even more important in Fano family. Two are the sons of Gino Fano: one is Robert Fano, born in 1917 and presently Professor Emeritus of Electrical Engineering and Computer Science at Massachussetts Institute of Technology.

The other one was Ugo Fano (1912-2001). Ugo Fano, Enrico Fermi award 1996 and Fermi's student and collaborator, is well known for his fundamental contributions to atomic physics. Let us quote some memories about him and his father from New York Times:

"Ugo Fano was born in Turin, Italy, on July 28, 1912. His father, Gino Fano, was a mathematician at the University of Turin, and he kept the young Ugo apprised of the great discoveries in physics and mathematics that were taking place around the world. In a memoir, Ugo Fano said he recalled being introduced to Niels Bohr's new atomic theory at the dinner table when he was $12 " 12$.

The latter remarks put in evidence the broadness of the scientific views of Fano. This is quite typical of great men of Science born at his times. However it is perfectly combined with his outstanding mathematical talent and the deep relations he had with the scientific milieu of his times.

To this respect, before of passing to the main stream of his algebro-geometric interests, the picture could be expanded in several directions, in order to appropriately describe the presence and the strong influence of Fano in the mathematical and scientific debate of his times.

Let us introduce just one more example of this fact. Here we refer to the intense debate on foundations of Geometry in the years preceding Hilbert's Grundlangen der Geometrie.

As is well known this debate was of special importance in Italy. The University of Torino became one of the main centers of it, due to the presence of Corrado Segre and Giuseppe Peano: two leading scholars with their own points of view on foundations of Geometry.

Many geometers contributed to this subject and the young Fano was among them. His ideas on projective geometry in arbitrary dimension are near

11 [1935-2]: Geometria non euclidea, (introduzione geometrica alla teoria della relatività generale).

12 J. Glanz Ugo Fano is dead at 88; Physicist linked to Fermi New York Times, February 152001. to Segre's ideas and to $n$-dimensional geometry of Bertini and Veronese.

They are neatly expressed in his paper of 1892 on foundations of projective geometry, where a famous model of projective plane, named today the Fano plane, is in particular constructed.

It is not our task to enter in the historical studies on those years, it is however appropriate for our description mentioning the relevance of this contribution given by Fano.

Indeed, about the Italian debate on foundations of Geometry, it is not rare to read comments in the same spirit of the following one, due to Jeremy Gray $^{13}$. He is essentially reporting Hans Freduenthal's point of view:

"When the distinguished mathematician and historian of mathematics Hans Freudenthal analysed Hilbert's Grundlagen he argued that the link between reality and geometry appears to be severed for the first time in Hilbert's work. However, he discovered that Hilbert had been preceeded by the Italian mathematician Gino Fano in 1892. Recent historians of mathematics have shown that, in Italy at least, Fano's point of view on the nature of geometrical entities had been a generally accepted theory for at least a decade, but it was not in fact axiomatic in Hilbert's manner; other Italian mathematicians were, however, ahead of Hilbert in this regard. How did this come about, what did they do, and why they lose out?"

We have stressed enough the wideness of Fano's views and his strength in the general field of geometry. Nevertheless Fano was mainly, though definitely not only, an algebraic geometer.

In particular he was immersed in the main stream of classical Italian school of algebraic geometry. This can be seen in many ways: for instance from the central role played by birational geometry in his views or from the attention he payed to classification of algebraic varieties.

Another example of this fact is certainly represented by his genuine and strong intuition in understanding the natural geometric life, so to say, of a projective variety living in an $n$-dimensional projective space. However, in the taste of Fano as an algebraic geometer and in his choices of investigation, something more is present which goes further.

Taking our sentence with a grain of salt, we can say that, often, he opened the way to problems, or to important geometric objects, which were quite unexplored or still untouched:

birational geometry in higher dimensions, algebraic groups of Cremona transformations, cubic threefolds and their irrationality, K3 and Enriques

13 J. Gray The Foundations of Projective Geometry in Italy Undergraduate Mathematics Series p. 269-279 Springer (2010). 
surfaces with special automorphisms, Fano threefolds, of course, and more.

\section{On Fano's Research and Scientific Heritage}

In what follows we enumerate the main research topics Fano addressed. Each of them is accompanied by a short note, whose purpose is to outline Fano's contribution and the periods of his work on the subject.

Each note consists of free and non systematic comments: we usually single out just one representative paper and use it to very briefly describe the subject and Fano's results. At the end of any subject we quote some relevant papers of Fano on it.

The subjects of the list follow, approximately, the chronological order of the scientific events in the life of Fano. If possible our aim is to capture, by a unique rapid sketch, much of Fano's scientific image.

\section{Foundations of Geometry}

This subject was specially cultivated by the very young Fano. As already remarked, his contribution is situated in a fertile area of research of those years, in particular in Italy ${ }^{14}$. His paper $[1892-1]^{15}$ is of relevant importance.

At that time $n$-dimensional projective spaces were currently in use, and investigated, via projective coordinates. However there weren't established foundations of this notion by a system of independent postulates, allowing in particular the use of coordinates. This important problem was raised by Corrado Segre $^{16}$ to his students, among them Fano, during his course "Geometria sopra un ente algebrico" in the academic year 1890-91.

In [1892-1] Fano constructs an adequate system of independent postulates for a projective $n$-space ${ }^{17}$ and, to confirm their independence, he comes to discover examples of finite projective spaces. By an ingenious construction he constructs in this way the projective plane over the field $\mathbb{Z} / 2 \mathbb{Z}$, still named the Fano plane. Notably these examples represent early sources for the field of finite geometry. Fano's ideas

14 To the mentioned names of G. Peano, C. Segre and G. Veronese, we should add at least those of F. Amodeo, F. Enriques, M. Pieri, G. Vailati and many others.

15 Sui postulati fondamentali della geometria proiettiva in uno spazio lineare a un numero qualunque di dimensioni.

16 See I Quaderni di Corrado Segre, CD-ROM edited by L. Giacardi, Dipartimento di matematica, Università di Torino, 2002.

17 Notably he says that points in this space are "entities which, for brevity, we shall call points, independently, however, from their nature", [1892-1] p. 109. on foundations of geometry are expressed in several papers, articles and letters.

Some contributions along the years: [1890-1, $1892-1,1895-3,1895-4,1899-4,1908-1,1910-1$, 1915-4, 1924-2, 1932-3, 1932-4, 1934-2, 1936-4, $1936-5,1938-2]$

\section{Algebraic Curves}

The theory of algebraic curves, whose place is a central one in the interests of the classical Italian school, shows a minor weight in the interests of Fano. Curves are everywhere in his papers, but rarely these are concerned with this theory.

A remarkable exception, influenced by the scientific exchange with Castelnuovo and Segre, is the paper [1893-2]. Actually this is part of "Dissertazione di Laurea"18, written by Fano under the direction of Segre and published in 1894.

It deals with curves $C$ of degree $d$ in a projective space $\mathbb{P}^{r}$. Two years before Castelnuovo had proved that the genus of $C$ is bounded and that the maximal genus $p(d)$ is reached by curves in a rational normal scroll or in the Veronese surface ${ }^{19}$.

Fano applies the same methods to characterize curves of genus near to $p(d)$. In particular he studies the linear system of quadrics through a curve $C$ of genus $p(d)-k$. Together with further results he deduces that, for $k=1, C$ is contained in a surface whose hyperplane sections are rational or elliptic. From this property the classification of curves $C$ in genus $p(d)-1$ follows.

Some contributions along the years: [1892-1, 1930-1, 1940-2]

\section{Continuous Groups in Projective and Birational Geometry}

Due to the activity of Klein and Lie, transformation groups were a central theme on the mathematical scene during the early years of Fano. He was well exposed to these ideas due to the scientific ties with Klein we mentioned. As a consequence, the theme of continuous groups of birational transformations represents a fundamental part of Fano's work. He was specially active on it in the five years before 1900. Although other contributions are possibly better known, this one consists of notes, memoirs and essays, for more than 300 pages, of maximal interest.

In the spirit of Erlangen program a leading project on the field was to understand projective varieties,

18 The thesis to be submitted by a university student for obtaining the degree.

19 G. Castelnuovo Ricerche di Geometria sulle curve algebriche 24, Atti Acc. Scienze Torino (1890). 
in the complex projective space $\mathbb{P}^{n}$, which are invariant by the action of any given Lie subgroup $G$ of $P G L(n+1, \mathbf{C})$. This research was started by Klein and Lie in $\mathbb{P}^{2}$ and $\mathbb{P}^{3}$. They were joined by Enriques and others in the same period. The classification came to completion before $1900^{20}$.

In two memoirs, [1895-11, 1896-3], Fano extends this classification to $\mathbb{P}^{4}$. It is not a kind of trivial step, he uses new ideas from geometry and representation theory. Actually, when $G$ is a non integrable ${ }^{21}$ continuous group, his method turns out to be the search in $\mathfrak{s l}(5, \mathbf{C})$ of Lie subalgebras isomorphic to $\mathfrak{s t}(2, \mathbf{C})$. He applies Study's complete reducibility theorem for $\mathfrak{s l}(2, \mathbf{C})$ and also gives a geometric proof of it. Then he can construct the beautiful series of $G$-invariant hypersurfaces.

A third fundamental memoir is a joint paper of Enriques and Fano, [1897-2]. It is of primary importance in the study of the Cremona group $\operatorname{Bir}\left(\mathbb{P}^{3}\right)$, the group of Cremona transformations, that is birational automorphisms, of $\mathbb{P}^{3}$. In it all the complex Lie subgroups of $\operatorname{Bir}\left(\mathbb{P}^{3}\right)$ are classified.

The authors show that, up to two exceptions, each of them is conjugated to a known subgroup of one of the following continuous groups: $P G L(4, \mathbf{C})$, the group of conformal transformations, the two types of groups defined by de Jonquiéres space transformations. The exceptions are two 3-dimensional groups respectively related to the octahedron and the hicosahedron.

Finally let us recall that de Jonquiéres transformations of $\mathbb{P}^{3}$ generalize those of $\mathbb{P}^{2}$ with the same name. They are of two types according to what they fix: a pencil of planes or a star of lines. In a fourth memoir Fano classifies all continuous groups of them, [1898-1]. This complements the joint memoir with Enriques.

Continuous groups of Cremona transformations were object of a communication by Fano at the first International Congress of Mathematicians, at Zurich in 1897.

Some contributions along the years: [1895-5, 1895-11, 1896-1, 1896-3, 1896-4, 1896-5, 1897-1, $1897-2,1897-3,1898-1,1898-6,1898-3,1898-4$, $1898-5,1899-6,1907-3]$

20 See: (1) F. Enriques "Le superficie con infinite trasformazioni proiettive in sè stesse” Atti R. Ist. Veneto 51 (1893) 1590-1635. (2) S. Lie "Bestimmung aller Flaechen, die eine continuierliche Schaar von projektiven Transformationen gestatten" in "Gesammelte Abhandlungen" Teubner, Leipzig (1922). Various contributions are due to Fano.

${ }^{21}$ In the classical language of Lie's theory integrable group precisely means solvable group, see Thomas Hawkins loc. cit. p. 91. Since this word often appears in the papers of Fano and in their titles, we have chosen to keep it.

\section{Algebraic Varieties Defined by Linear Differential Equations}

This topic represents a very important contribution due to Fano. It is coherent with the previous one on continuous groups and it was developed in the same years. In particular, it can offer to the reader a more precise and comprehensive focus on the real features and complexity of Fano's work in its historical frame.

This contribution reflects once more the influence of the circle of ideas arising from the impulse of Lie's work, that is, the foundations of Galois theory of linear differential equations ${ }^{22}$. From this point of view Fano was developing the classical theory of Picard-Vessiot, as he explains in [1899-2] and in other papers.

Fano applies this theory to the remarkable case where there exists a non zero homogeneous polynomial $F \in \mathbf{C}\left[T_{1} \ldots T_{n}\right]$ which is identically zero on a set of $n$ independent solutions $y_{1} \ldots y_{n}$ of a given linear differential equation $L=0$.

The Galois group of $L=0$ acts linearly on the projective subvariety $M \subset \mathbb{P}^{n-1}$, defined by all the polynomials $F$. Moreover, the maximal continuous group of projective transformations fixing $M$ yields most of the informations about the integration of $L=0$. This relates the study of $L$ to the classification of projective varieties which are invariant by a continuous subgroup of Aut $\mathbb{P}^{n-1}$.

Most of Fano's results on this topic converge to a fundamental paper, published by him in Mathematische Annalen, [1900-1]. Notably this paper, as well as his entire work in the field, were reconsidered by Michael Singer. Singer offers a very clear description of Fano's contribution in his paper Algebraic Relations Among Solutions of Linear Differential Equations: Fano's Theorem ${ }^{23}$, published in 1988. Let us freely summarize from it:

Assume $L=0$ is homogeneous with complex rational functions as coefficients. Then, with the previous notations, consider the following statement:

(*) If there exists a non zero $F \in \mathbf{C}\left[T_{1} \ldots T_{n}\right]$ such that $F\left(y_{1} \ldots y_{n}\right)=0$, then all solutions of $L=0$ can be expressed as algebraic combinations of solutions of linear differential equations of order $\leq n-1$.

A major Fano's contribution is the theorem that (*) is true for $n \leq 5$. He also gave partial positive results for $n \geq 6$. Due to these and later results $\left.{ }^{24},{ }^{*}\right)$ was

22 Cfr. M. van der Put, M. F. Singer Galois theory of linear differential equations Grundlehren Math. Wiss. vol. 328 Springer Berlin (2003).

23 M. Singer in American Journal of Math. 110 (1988) 115-143.

24 Cfr. D.V. Chudnovsky, G.V. Chudnovsky The wronskian formalism for linear differential equations and Pade approximation Advances in Math. 53 (1984) 28-54. 
expected to be true for $n \geq 6$. Finally Singer showed that (*) is true for $n=6$ and false for $n \geq 7$.

Fano's approach to (*) is very explicit and beautiful. He uses group theoretic and projective geometric techniques to detect the possible algebraic relations satisfied by $y_{1}, \ldots, y_{n}$ for $n \leq 5$. Then he relies on his deep knowledge of projective varieties in $\mathbb{P}^{n-1}$, $n \leq 4$, which are invariant by a continuous subgroup of Aut $\mathbb{P}^{n-1}$.

Some contributions along the years: [1895-8, 1895-6, 1895-7, 1895-9, 1895-10, 1899-1, 1899-2, 1899-3, 1899-5, 1900-1]

\section{Line Geometry}

Line geometry is the study of the Grassmannian $G\left(1, \mathbb{P}^{n}\right)$ of lines of a projective space $\mathbb{P}^{n}$. Around 1900 Fano dedicated his best to this subject, aiming to continue the classification of congruences of lines started by Kummer over the complex field ${ }^{25}$. A congruence of lines is just a surface $S$ in $G\left(1, \mathbb{P}^{3}\right)$. Its cohomology class defines a pair of integers $(a, b)$, known as the type of $S$.

At that time, after a long work, the classification of congruences of lines was known for $a \leq 2$. Its extension to the case $a=3$ was essentially realized by Fano in the very rich paper "Congruenze di rette del $3^{\circ}$ ordine prive di linea singolare", [1900-1], and in some related papers.

Notably Fano abandons, at least partially, the study in $\mathbb{P}^{3}$ of families of lines. His modern geometric approach is openly declared ${ }^{26}$ : to consider and study these families as subvarieties of the appropriate space for line geometry. This means the Plücker embedding of $G\left(1, \mathbb{P}^{3}\right)$ that is the Klein quadric in $\mathbb{P}^{5}$.

Our distance from Fano's results is not big: problems on congruences of lines and their classification are still widely open.

Line geometry of $\mathbb{P}^{n}$ is moreover considered by Fano in two remarkable cases. They are related to cubic hypersurfaces in $\mathbb{P}^{4}$, a crucial topic of his investigations.

For $n=4$ he studies the family $F(V)$ of all lines contained in a smooth cubic hypersurface $V \subset \mathbb{P}^{4}$, [1904-1]. $F(V)$ is a surface, known as the Fano surface of $V$.

For $n=5$ he studies the general 3-dimensional linear section of the Plücker embedding of $G\left(1, \mathbb{P}^{5}\right)$, proving that it is birational to a general cubic $V$, [1930-2].

Some contributions along the years: [1893-1, 1894-1, 1896-2, 1900-1, 1901-2, 1901-4, 1904-1, 1905-1, 1922-1, 1930-4, 1930-2]

25 E. Kummer "Ueber algebraische Strahlen systeme, insbesondere ueber di der ersten und zweiten Ordnung" Berliner Abh. 1866.

26 "Studio di alcuni sistemi di rette considerati come superficie dello spazio a cinque dimensioni" is the title of [1893-1].

\section{Non Rationality and Birational Geometry in Dimension 3}

In 1876 Lüroth proved that a unirational complex curve is also rational. The extension of this theorem to higher dimensions became few years later the Lüroth problem. In 1892 this was positively answered in dimension two by a brilliant theorem of Castelnuovo $^{27}$. As is well known the negative answers to Lüroth problem in dimension $\geq 3$ are a central episode of XX century algebraic geometry.

In the paper [1908-2] Fano gives a proof of non rationality for a general quartic hypersurface in $\mathbb{P}^{4}$ and for a general quadro-cubic complete intersection in $\mathbb{P}^{5}$. Though his proof is not satisfactory from a modern point of view, the main ideas behind it are the correct ones.

They were fruitfully cultivated by the Russian school of Manin and Iskovskih. The non rationality of the quartic then followed by Iskovskih and Manin in $1971^{28}$. Later the same method of birational rigidity was successfully applied by Pukhlikov to the other threefold ${ }^{29}$.

Fano's approach to this problem is today encoded in the notion of birational rigidity and relies on a technique for the factorization of a birational map which is known as Noether-Fano inequality ${ }^{30}$. The prototype of it is the inequality, due to Noether, used for proving that every Cremona transformation of the plane factors through quadratic and linear transformations.

In the related paper [1915-1] Fano improves his program in order to prove the non rationality of a threefold $V$ as above. He proposes a new, very modern, idea: to study the linear systems of K3 surfaces existing on $V$ to deduce its birational rigidity and hence its irrationality.

On the other hand, since $V$ is in the series of Fano threefolds, the question of its unirationality of is natural. If $V$ is a general quadro-cubic complete intersection this was proved by Enriques in 1912. Hence $V$ represents in this case a negative answer to Lüroth problem. Still today the unirationality of a general quartic of $\mathbb{P}^{4}$ is instead an outstanding open problem.

It is due to mention in this section the interest of Fano for developing further techniques of

\footnotetext{
27 See: G. Castelnuovo "Sulla razionalitá delle involuzioni piane" 1894, Math. Annalen 44 (1894) 125-155.

${ }^{28}$ For a general picture see the volume "Algebraic Geometry $V$ - Fano Varieties" by V. Iskovskikh and Yu. Prokhorov in Encycl. of Math. Sciences. v. 47 (1991) Springer Berlin.

29 A. Pukhlikov "Maximal singularities on the Fano variety $V_{6}^{3}$ ” Moscow Univ. Math. Bull. 44 (1989) In this case, however, Beauville had already proven the non rationality via the intermediate jacobian. 70-75. A. Beauville "Variètès de Prym et jacobiennes intermèdiaires” Ann. Sci. Ec. Norm. Sup. 10 (1977) 309-391, thm. 5.5.

30 See the mentioned book "Algebraic Geometry V - Fano Varieties", Lemma 9.9.1.
} 
3-dimensional birational geometry. This is a motivation for his work on the classical theory of contact birational transformations of the plane, which is of projective-differential geometric flavor.

Let $\mathbb{P} \Omega_{\mathbb{P}^{2}}^{1}$ be the projectivized cotangent bundle of $\mathbb{P}^{2}$. These transformations can be defined as birational automorphisms $a$ of $\mathbb{P} \Omega_{\mathbb{P}^{2}}^{1}$ such that $p \cdot a=b \cdot p$, where $p: \mathbb{P} \Omega_{\mathbb{P}^{2}}^{1} \rightarrow \mathbb{P}^{2}$ is the natural projection and $b \in$ $\operatorname{Bir}\left(\mathbb{P}^{2}\right)$. Since $\mathbb{P} \Omega_{\mathbb{P}^{2}}^{1}$ is rational, $a$ is birationally equivalent to an element of $\operatorname{Bir}\left(\mathbb{P}^{3}\right)$.

To this, quite unexplored, topic is dedicated one of the two communications of Fano to the International Congress of Mathematicians of 1928.

Some contributions along the years : [1898-1, $1898-3,1899-6,1908-2,1915-1,1915-2,1918-1$, $1928-1,1928-2,1931-2,1932-1,1942-1,1942-2$, $1947-1,1950-3]$

\section{Cubic Threefolds}

Cubic hypersurfaces in the complex 4-dimensional projective space are usually called cubic threefolds. They are definitely associated to Fano's biography, since he was studying cubic threefolds systemically for a very long period, with a special attention towards the problem of their irrationality.

Since the unirationality of a smooth cubic threefold $V$ was known ${ }^{31}$, proving its irrationality was sufficient for Fano to negatively answer Lüroth problem. This was of course one of his motivations for studying cubic threefolds. In the late survey [1950-3] of 1950 Fano describes his approach to the irrationality of $V$ and many other aspects of his work on cubic threefolds.

This begun around 1904: in this year he publishes four papers on cubic threefolds where various fundamental properties are established. He shows that the Picard group of a smooth $V$ is generated by the hyperplane class, so that every surface in $V$ is complete intersection. Also, he studies in detail the dual hypersurface and more properties of a general of $V$.

Another cornerstone is his study of the family of lines contained in $V$. This is a surface $F(V) \subset G\left(1, \mathbb{P}^{4}\right)$, known as the Fano surface of $V$. As is well known it plays a crucial role in the proof of the irrationality of $V$ due to Clemens and Griffiths via the method of the intermediate jacobian ${ }^{32}$. It is worth mentioning a geometric investigation by Fano which is quite connected to this method. It is the study of plane quartics

31 Virgil Snyder in "The problem of the cubic variety in $S_{4}$ ", (Bull. AMS 35 (1929) 607-642) says that this property was known to Max Noether.

${ }^{32} \mathrm{H}$. Clemens, P. Griffiths "The intermediate jacobian of the cubic threefold” Annals of Math. 95 (1972) 281-356. which are everywhere tangent to a given plane quintic, [1940-2].

Actually any line in $V$ defines one of these families of quartics. Moreover the theta divisor $\Theta$ of the intermediate jacobian of $V$ can be reconstructed from the corresponding family of even theta characteristics of these quartics. In modern terms he considers families of even spin curves of genus 3 which are birational to the quotient of $\Theta$ by -1 multiplication.

Soon Fano realized that the methods of birational geometry he could use at his time were not satisfactory in the case of $V$. This opened the way to him for studying more properties of $V$ and a wider series of threefold relatively similar to $V$.

Today these are named Fano threefolds. The 3-dimensional linear section $V^{\prime}$ of the Plücker embedding of the Grassmannian $G\left(1, \mathbb{P}^{5}\right)$ is one of them. Fano proves the beautiful result that a general $V$ is birational to some $V$ ' and conversely. Then he gives a proof of the irrationality of $V^{\prime}$ via the methods mentioned in the previous subject.

Some contributions during the years: [1904-1, 1904-2, 1904-3, 1904-4, 1915-1, 1918-1, 1930-4, 1930-2, 1940-2, 1943-1, 1944-1, 1946-1, 1950-3]

\section{Fano Threefolds}

A smooth projective variety $V$ is a Fano variety if its first Chern class is ample. The definition suitably extends to a singular $V$. In contemporary algebraic geometry Fano varieties are among the fundamental elements for the birational classification of algebraic varieties of any dimension. They bear the name of Fano because of his pioneering work in the classification of Fano threefolds i.e. 3-dimensional Fano varieties.

Starting from the study of the irrationality problem for some of these threefolds, like for instance cubic threefolds, the activity of Fano on this subject developed along forty years. After his death the investigations on Fano threefolds became a fundamental direction of algebraic geometry, culminating in the complete classification of them, based on modern methods and on Mori theory ${ }^{33}$. Nonetheless Fano's previous contributions to this classification are everywhere present and recognized as invaluable. In 1928 his first results were communicated to the International Congress of Mathematicians held in Bologna.

In two memoirs of 1937 he gave a bound on the degree of Fano threefolds, thus proving that they are distributed in finitely many families. He also proved most of the possible rationality results for Fano threefolds. Later he recollected most of his work in the memoir "Nuove ricerche sulle varietá algebriche a tre dimensioni a curve sezioni canoniche", published in 1948.

33 See again Algebraic Geometry V - Fano Varieties. 
In it one finds a deep geometric description of all the families he had previously considered. Another part is dedicated to Lüroth problem and to the irrationality problem for the members of some of these families.

Fabio Conforto, an emerging algebraic geometer of that time, made a lucid and fascinated analysis of this memoir in a long review ${ }^{34}$. It is interesting to read in it the profound value he attributes to this work, even if he remarks some known limits reached by the classical methods in use.

Some contributions along the years : [1904-2, 1908-2, 1930-4, 1930-2, 1931-3, 1932-1, 1935-3, 1936-1, 1936-2, 1937-1, 1937-2, 1942-1, 1942-2, 1945-1, 1946-1, 1948-1, 1949-1, 1950-3]

\section{Fano-Enriques Threefolds}

Let $V \subset \mathbb{P}^{n}$ be a Fano threefold. One says that $V$ is anticanonically embedded if its first Chern class is the class of its hyperplane sections. In this case a general hyperplane section of $V$ is a K3 surface $^{35}$. The interest of Fano for K3 surfaces has certainly one motivation in his thorough investigations on linear systems of K3 surfaces on a Fano threefold. Another motivation, we rediscover in the next section, is his ancient curiosity for automorphisms groups in algebraic geometry.

Enriques surfaces are very related to K3 surfaces: an Enriques surface is the quotient of a K3 surface endowed with a fixed point free involution. Now, in the world of Fano threefolds, it appears that some of them admit an involution with finitely many fixed points, namely eight.

Taking the quotient of such a threefold by such an involution, one obtains a threefold $V$ which is a Fano threefold again. It is of special type. In particular, a birational projective model of $V$ is a threefold $V$ ' whose hyperplane sections are Enriques surfaces. Today we say that $V^{\prime}$ is an Enriques-Fano threefold, just because its hyperplane sections are Enriques surfaces.

Enriques-Fano threefolds are a kind of geometric jewels in the landscape we are describing. Fano met the study of them in the memoir, [1938-1]. His results parallels those of Godeaux ${ }^{36}$ in the same years.

He proves that $V^{\prime}$ is birational to a Fano threefold. Then he gives a beautiful geometric classification of these threefolds $V^{\prime}$. This is however based on a restrictive hypothesis on the eight singular

${ }^{34}$ F. Conforto Mathematical Reviews MR0038100.

${ }^{35}$ A K3 surface is a compact complex surface which is simply connected and such that its first Chern class is zero.

36 L. Godeaux "Sur les varietés algébriques à trois dimensions dont les sections sont des surfaces de genre zéro e de bigenre ” un' Bull. Acad. Belgique, Cl. des Sci. 14 (1933) 134-140. points present in $V^{\prime}$. Fano-Enriques threefolds were essentially rediscovered in the eighties ${ }^{37}$. As in the case of Fano threefolds, the work of Fano, though not bringing a complete classification, strongly influenced modern investigations, which became flourishing on this topic. ${ }^{38}$

Some contributions along the years: [1938-1, 1944-2]

\section{K3 or Enriques Surfaces and Their Automorphisms}

The automorphisms groups of $\mathrm{K} 3$ or Enriques surfaces are discrete, trivial for a general K3. The work of Fano on these groups of automorphisms is linked to quartic surfaces and also to his investigations on line geometry.

In 1906 Enriques proved the following theorem: every surface having a non finite, discrete group of automorphisms is either elliptic or a K3 surface. In the same year Fano constructs the first example of a non elliptic K3 surface of this type.

It is a quartic surface of Picard number two containing a smooth sextic of genus two, [1906-1]]. His conjectural remark on the existence of infinite series of families of examples, distinguished by numerical characters, is completely confirmed. Later he came to enlarge the picture constructing several families, see [1920-1, 1920-2, 1920-3, 1920-4, 1920-5, 1943-2, 1950-1].

But a beautiful jewel was constructed by him when studying automorphisms of Enriques surfaces. Enriques surfaces are elliptic. Moreover, as observed by Enriques, the group of automorphisms is not finite for a general Enriques surface.

In particular it could appear almost unbelievable, or at least not obvious, that this group could become finite for special elements in the family of all Enriques surfaces $^{39}$. In 1910 Fano produced an example of this type, [1910-2].

The example is a very special case of Reye congruence. A Reye congruence $S$ is a special Enriques surface embedded in the Grassmannian $G\left(1, \mathbb{P}^{3}\right)$. Its Plücker embedding is known as an example of Fano model of an Enriques surface ${ }^{40}$.

37 A. Conte J.P. Murre "Algebraic varieties of dimension three whose hyperplane sections are Enriques surfaces" Ann. Sc. Norm. Sup. (4) 12 (1985) 43-80.

38 See for instance: Y. Prokhorov On Fano-Enriques varieties Sb. Math. 198 (2007) 559-574 and A. Knutsen, A. Lopez, $\mathrm{R}$. Munoz On the extendability of projectives surfaces and a genus bound for Enriques-Fano threefolds J. Diff. Geom. 88 (2011) 485-518.

39 Cfr. V. Nikulin "On algebraic varieties with finite polyhedral Mori cone" in The Fano Conference, Editors A. Collino, A. Conte, M. Marchisio. printed by Universitá di Torino, Dipartimento di Matematica Torino (2004) 573-589, section 3. 40 F. Cossec, I. Dolgachev-Cossec "Enriques Surfaces I" 
Roughly speaking the very special $S$ considered has an elliptic pencil which is invariant by Aut $S$ and moreover contains a very special element $F . F$ is a suitable configuration of rational curves, which is invariant by Aut $S$. The existence of such an $F$ forces Aut $S$ to be finite.

Enriques surfaces with a finite group of automorphisms disappeared from the scene after the isolated construction of Fano. One had to wait the eighties of $\mathrm{XX}$ century for their rediscovery. This was done by Igor Dolgachev in 1983. Further results and the classification followed ${ }^{41}$. Later Fano's example was rediscovered by Dolgachev himself and discussed from a modern point of view.

Some contributions along the years: [1897-3, 1906-1, 1910-2, 1920-1, 1920-2, 1920-3, 1920-4, 1920-5, 1938-1, 1943-2, 1944-2, 1950-1]

\section{Epilogue}

For most of his life Gino Fano was professor of projective and descriptive geometry at the University of Torino. More precisely he was professor there since 1901 until the year 1938.

In this year he lost his job due to the racist laws against Jews established by the fascist regime. Then he had to leave the country. He was reintegrated in his job in 1946, after the end of World War II.

In contrast to these obscure years, it is perhaps the right moment for mentioning the deep and positive influence of Fano, as a person and as a teacher, on so many persons and brilliant students, as well as mentioning the sign he left during the long years spent as a professor.

In the year 1950 a group of persons, made by former students and friends, organized in Torino a series of lectures by him as a homecoming celebration in his honor. Reading the list of these persons, in the volume of this event, is impressive, and instructive of the above mentioned influence of Fano.

In the list, together with other famous mathematicians, one can see the name of Beniamino Segre. His words can serve as an epilogue for a long, great life in geometry. Perhaps they can serve for an entire geometric age, in the years of transition from older to newer algebraic geometry:

“... con riconoscenza ed ammirazione al Professor Gino Fano, le cui smaglianti lezioni di Geometria proiettiva - nel lontano 1919-20 - ebbero su di me un effetto decisivo, attraendomi irresistibilmente verso gli studi geometrici." 42

Birkhaüser, Boston (1989) p. 279 and I. Dolgachev "A brief introduction to Enriques surfaces", conference in honor of S. Mukai http://www.math.lsa.umich.edu/ idolga/Kyoto13.pdf.

41 See: I. Dolgachev "On automorphisms of Enriques surfaces" Invent. Math. 76 (1984) 163-177, W. Barth, C. Peters "Automorphisms of Enriques surfaces”, 73 Invent. Math. (1983) 383-411.

\section{Gino Fano: 1871-1952}

1871 Gino Fano ${ }^{43}$ was born on January 5, 1871, in Mantova, Italy. ${ }^{4}$

1871 In the same year and day Federigo Enriques was born in Livorno.

1871 Rome is the new capital city of the Kingdom of Italy.

1880-87 Fano has a brilliant career as a student in various schools. ${ }^{45}$

1888-92 Student at University of Torino, Fano is pupil and friend of Segre and Castelnuovo. Suggested by Segre, he translates Klein's Erlangen Program.

1892 June 22: Fano is proclaimed Dottore in Matematica, his advisor is Segre. ${ }^{46}$ The contents of his Dissertazione di laurea become a published paper, [1893-2].

1892-93 Assistant of E. d'Ovidio at the University of Torino. First contributions to foundations of geometry and to line geometry.

1893-94 Academic year spent in Goettingen under the invitation of Felix Klein.

1894-95 Assistant of G. Castelnuovo in Rome. Contacts with Luigi Cremona and various mathematicians in Rome.

1892-97 Several contributions to: continuous groups and their invariant projective varieties, geometric properties of linear differential equations, line geometry.

1897 First International Congress of Mathematicians, Zurich: communication by Fano on continuous groups of Cremona transformations.

42 "... with gratitude and admiration to Professor Gino Fano, whose brilliant lectures on projective geometry - back in 1919-20 - had a decisive effect on me, irresistibly drawing me toward geometric studies.” B. Segre "Intorno agli spazi lineari situati sulle quadriche di un iperspazio" Rend. Sem. Mat. Univ. e Polit. di Torino 9, 1949-50, 137-144.

43 For further bio-bibliographical informations we quote and suggest the very interesting monography Sull'apporto evolutivo dei matematici ebrei mantovani nella nascente nazione italiana,by A. Janovitz and F. Mercanti, Monografie di EIRIS(2008), rivista on line www.eiris.it.

44 Gino Fano is the son of Ugo Fano and Angelica Fano. His family was a wealthy Jewish family rooted in Mantova. His father volunteered with Garibaldi. His mother was quite engaged in defense of Italian Culture and member of "Dante Alighieri" Society.

45 1880-83: Fano studied at Liceo-ginnasio Virgilio in Mantova. Obeying his father, he started a military career. Then he left it for the section of Physics and Mathematics of R. Istituto A. Pitentino in Mantova, where he brilliantly obtained his diploma and a special prize as an excellent student.

46 The committee: G. Basso, E. d'Ovidio, N. Jadanza, G. Peano, M. Pieri and C. Segre. The grade given to Fano was maximal: 90/90 cum laude. 
1899 Fano wins a position of professor on the chair of algebra and analytic geometry of the University of Messina.

1899 A position of professor in Goettingen, starting from December 1st 1899, is offered by Klein to Fano. However he will decline this offer. ${ }^{47}$

1899 Hilbert's Grundlagen der Geometrie.

1899 Social conflicts and industrialization in Italy. July 11: opening of FIAT, Fabbrica Italiana di Automobili Torino. 8 cars are produced in 1899.

1900 Second International Congress of Mathematicians: Hilbert's problems.

1901 Fano becomes professor in the University of Torino, on the chair of projective and descriptive geometry.

1897-03 Memoirs on continuous groups of Cremona transformations. Memoirs on order 3 congruences of lines. Notes and long papers on linear differential equations whose solutions satisfy algebraic relations.

1904 First papers on the cubic threefold: a series of four papers. One of them describes the Fano surface of lines of a cubic threefold.

1904 11-th Summer Meeting of American Mathematical Society, St. Louis: Henry Poincaré and Gino Fano are special invited guests of the Meeting.

1905 Albert Einstein's Annus Mirabilis ${ }^{48}$

1905 Fano begins his cooperation, as a teacher and as an organizer, to the Evening School for Women Workers of Torino. ${ }^{49}$ See his report on the period 1909-10.

1907 Two important contributions of Fano to Enzyclopaedie der Mathematische Wissenschaft, see [1907-2, 1907-3]

1907-11 First papers on K3 or Enriques surfaces, in particular on their automorphisms. First papers on the rationality problem for some Fano threefolds.

1911 Torino: Gino Fano marries Rosa Cassin (1880-1956). They will have two sons, Ugo (1912-2001) and Robert (1917 - -).

1912 Birth of his son Ugo, a future prominent scientist in Physics. Student of Fermi and Heisenberg, he will be Professor Emeritus of the University of Chicago and Fermi award 1995.

47 According to Fano's son Ugo, his father “... did not want to be Germanized".

${ }^{48}$ Four revolutionary papers published by Einstein in 1905 on Photoelectric effect, Brownian motion, Special relativity, Mass-energy equivalence.

${ }^{49}$ For his action in favor of the School and Public Education, Fano will get the golden medal of "Benemerito della Pubblica Istruzione" in 1928.
1913 Niels Bohr introduces a quantum model of the atom.

1914 Elie Cartan writes an extended French translation of Fano's contribution to Enziklopaedie der Mathematische Wissenschaft on continuous groups.

1915 Further papers by Fano, after those on cubic threefolds and [1908-2], on three dimensional algebraic varieties with all plurigenera equal to zero. This theme, that is the theme of Fano threefolds, will accompany him for the rest of his life.

1914-18 First World War. Engaged as a lieutenant, Fano is also office manager of the Piedmont Committee for industrial mobilization. ${ }^{50}$ For his service he was given the prestigious title of "Ufficiale dell'Ordine della Corona d'Italia".

1917 Birth of his son Roberto, a future prominent scientist in Computer Science. He is Professor Emeritus at Massachussetts Institute of Technology. Shannon award 1976 for his work on Information theory and Electrical Engineering.

1922 University of Torino: Fano gives the inaugural lecture for the beginning of the academic year.

1922 Mussolini is prime minister after the fascist coup "Marcia su Roma".

1923 University College of Wales, Aberystwyth. Fano gives a series of invited lectures on the achievements of the Italian research in geometry and two general lectures: "Intuition in Mathematics" and "All Geometry is theory of Relativity" 51

1925 USSR: celebration of the 200 years of the Academy of Science. Gino Fano and Guido Fubini represent the University of Torino.

1926 Kazan USSR: Fano gives a talk at the Conference for celebrating Lobachetvskij after 100 years of non euclidean geometries.

1928 International Congress of Mathematicians, Bologna: two communications are presented by Fano. One is on Fano threefolds and their classification and the other one on plane birational contact transformations, see section 2.

\footnotetext{
${ }^{50}$ He was also editor of a book reporting the activities of the Committee during the war: L'opera del Comitato Regionale di Mobilitazione Industriale per il Piemonte (Settembre 1915 - marzo 1919).

51 Parts of the corresponding manuscripts are contained in the Fondo Fano of the mathematical library of University of Torino. See also: L. Giacardi Testimonianze sulla Scuola italiana di geometria algebrica nei fondi manoscritti della Biblioteca "Giuseppe Peano" di Torino in "Gli archivi della scienza. L'Universitá di Torino e altri casi italiani” (S. Montaldo, P. Novaria editors) Franco Angeli Milano (2011) 105-119.
} 
1931 All the professors of the Italian universities are required to pledge their loyalty to the fascist regime. ${ }^{52}$

1937 All public clerks must be members of the National Fascist Party.

1928-38 Several important papers are written by Fano on threefolds whose curvilinear sections are canonical curves, (Fano threefolds), and related topics.

1928-38 Several contributions are offered by Fano to "Istituto della Enciclopedia Italiana" and to "Enciclopedia delle Matematiche Elementari". His book "Geometria non euclidea (Introduzione geometrica alla teoria della relativitá)" is published.

1938 October 16: due to the racist laws against Jews, Fano is expelled from the ranks as a professor and from all Italian scientific institutions and academies. ${ }^{53}$

1939 Fano and his wife finally decided to leave the country for Switzerland. His son Robert left few weeks later, reaching Bordeaux and then the U.S. in September 1939. The other son, Ugo Fano, came also there in the same year.

1939-45 Refugee in Lausanne, Fano cooperates with the local University and the École des Ingènieurs. He gives courses for the Italian university students of the refugees camps. Conferences at the "Cercle mathématique de Lausanne".

1940-45 Papers in: Commentarii Mathematici Helvetici, Revista de la Universidad Nacional de Tucumàn, the journals of Pontificia Academia Scientiarum.

1940-45 Some topics: cubic threefolds and plane quintics. Cubic fourfolds with respect to rationality problem. ${ }^{54}$ Enriques surfaces (Reye congruences).

1946 Fano is back to Italy, restituted to his rights and status. He is retired and professor emeritus. He will spend most of his time in the U.S., visiting his sons.

1948 Fano's last important memoir appears in Commentationes Pontificiae Acad. Sci.: it is on classification and rationality problems for Fano threefolds.

1950 Torino, February: a conference in honor of Fano, including a series of five lectures by him, is organized at Seminario Matematico by his formers students. ${ }^{55}$

52 This happened with 12 exceptions.

53 A list of them: R. Accademia delle Scienze di Torino, R. Accademia dei Lincei, R. Istituto Lombardo di Scienze e Lettere, R. Accademia Peloritana di Messina, Circolo Matematico di Palermo, Unione Matematica Italiana, Societá Italiana per il Progresso delle Scienze, R. Accademia Virgiliana di Mantova.

${ }^{54}$ This is related to some results of Ugo Morin on the Pfaffian cubic fourfolds.

${ }^{55}$ For the list of organizers see Rend. Sem. Mat. Univ. Polit. Torino 9 (1950) 5-7.
1952 The last work of Fano was the preparation of the commemorative talk at Accademia dei Lincei for his friend Guido Castelnuovo, dead on April 271952.

1952 It will be impossible for him to give this talk. Fano passed away before of the commemoration, in Verona on November 8, 1952.

\section{Publications of Gino Fano 1890-1953}

In the next list of references we give the bibliographical coordinates of all papers written by Gino Fano we are aware of. The symbol * means that the paper is already present in the collection of scanned papers at the site Biblioteca Digitale Italiana di Matematica: http://www.bdim.eu/index

\section{References}

[1890-1] * Felix Klein, Considerazioni comparative intorno a ricerche geometriche recenti, Annali Mat. Pura Appl. 17 (1890) 307-343. (Fano's translation of Erlangen Program)

1892

[1892-1] * Gino Fano, Sui postulati fondamentali della geometria in uno spazio lineare ad un numero qualunque di dimensioni, Giornale di matematiche 30 (1892) 106-132

1893

[1893-1] * Gino Fano, Studio di alcuni sistemi di rette considerati come superficie dello spazio a cinque dimensioni, Annali Mat. Pura Appl. 21 (1893) 141-192

[1893-2] * Gino Fano, Sopra le curve di dato ordine e dei massimi generi in uno spazio qualunque, Memorie R. Acc. Sci. Torino 41 (1893) 335-382

1894

[1894-1] * Gino Fano, Sulle congruenze di rette del terzo ordine prive di linea singolare Atti R. Acc. Sci. Torino 29 (1894) 474-493

[1894-2] Gino Fano, Sull'insegnamento della matematica nelle Università tedesche $e$ in particolare nell'Università di Gottinga, Rivista di Matematica 4 (1894) $170-188$

1895

[1895-1] Gino Fano, Uno sguardo alla storia della matematica, Atti e Memorie R. Acc. Virgiliana (1895) 3-34

[1895-2] Gino Fano, Contributo alla teoria dei numeri algebrici, osservazioni varie e parte $I X$ del Formulario, Rivista di Matematica 5 (1895) 1-10

[1895-3] * Gino Fano, Sui postulati fondamentali della Geometria projettiva I Rendiconti Cir. Mat. Palermo 9 (1895) 79-82

[1895-4] * Gino Fano, Sui postulati fondamentali della Geometria projettiva II Rendiconti Cir. Mat. Palermo 9 (1895) 84-85

[1895-5] * Gino Fano, Sulle superficie algebriche con infinite trasformazioni projettive in sé stesse Rendiconti Acc. Naz. Lincei (V) 41 (1895) 149-156

[1895-6] * Gino Fano, Sulle equazioni differenziali lineari del IV ordine, che definiscono curve contenute in superficie algebriche, Rendiconti Acc. Naz. Lincei 41 (1895) 232-239 
[1895-7] * Gino Fano, Sopra certe curve razionali in uno spazio qualunque, e sopra certe equazioni differenziali lineari, che con queste curve si possono rappresentare, Rendiconti Acc. Naz. Lincei (V) 41 (1895) 51-57

[1895-8] * Gino Fano, Sopra alcune considerazioni geometriche che si collegano alla teoria delle equazioni differenziali lineari, Rendiconti Acc. Naz. Lincei (V) 4 (1894) $18-25$

[1895-9] * Gino Fano, Ancora sulle equazioni differenziali lineari del IV ordine, che definiscono curve contenute in superficie algebriche, Rendiconti Acc. Naz. Lincei 41 (1895) 292-300

[1895-10] * Gino Fano, Sulle equazioni differenziali lineari di ordine qualunque che definiscono curve contenute in superficie algebriche, Rendiconti Acc. Naz. Lincei 41 (1895) 322-330

[1895-11] * Gino Fano, Sulle varietà algebriche dello spazio a quattro dimensioni con un gruppo continuo integrabile di trasformazioni proiettive in sé, Atti Ist. Veneto Scienze, Lettere, Arti 7 (1895-96) 1069-1103

1896

[1896-1] Gino Fano, Ueber endliche Gruppen linearer Transformationen einer Veraenderliche, Monatsh. f. Math. 7 (1896) 297-320

[1896-2] Gino Fano, Aggiunta alla Nota: Sulle congruenze di rette del terzo ordine prive di linea singolare, Atti R. Acc. Sci. Torino 31 (1896) 708-715

[1896-3] * Gino Fano, Sulle varietà algebriche con un gruppo continuo non integrabile di trasformazioni proiettive in sé,Memorie R. Acc. Sci. Torino 46 (1896) 187-218

[1896-4] Gino Fano, Sui gruppi continui di trasformazioni cremoniane del piano e sopra certi gruppi di trasformazioni projettive, Rendiconti Circ. Mat. Palermo 10 (1896) 16-29

[1896-5] * Gino Fano, Sulle superficie algebriche con un gruppo continuo transitivo di trasformazioni proiettive in sé, Rendiconti Circ. Mat. Palermo 10 (1896) 1-15

[1896-6] Gino Fano, Lezioni di geometria della retta, L. Laudi Rome (1896) (lithographic printing)

\section{7}

[1897-1] Gino Fano, Ueber Gruppen, insbesondere continuierliche Gruppen von Cremona-Transformationen, der Ebene und des Raumes, Monatsh. f. Math. 9 (1897) $17-29$

[1897-2] * Federigo Enriques, Gino Fano, Sui gruppi continui di trasformazioni cremoniane dello spazio, Annali Mat. Pura Appl. 26 (1897) 59-98

[1897-3] * Gino Fano, Un teorema sulle superficie algebriche con infinite trasformazioni proiettive in sé, Rendiconti Circ. Mat. Palermo 11 (1897) 241-246

1898

[1898-1] * Gino Fano, I gruppi di Jonquières generalizzati Memorie R. Acc. Scienze di Torino, 48 (1898) 221-278

[1898-2] Gino Fano, Lezioni di geometria non euclidea, Rome (1898) (lithographic printing)

[1898-3] * Gino Fano, Le trasformazioni infinitesime dei gruppi cremoniani tipici dello spazio Rendiconti Acc. Naz. Lincei 71 (1898) 332-340

[1898-4] * Gino Fano, I gruppi continui primitivi di trasformazioni cremoniane nello spazio Atti R. Acc. Sci. Torino 33 (1898) 480-504

[1898-5] * Gino Fano, Sopra alcuni gruppi continui imprimitivi di trasformazioni puntuali dello spazio, Rendiconti Acc. Naz. Lincei 71 (1898) 302-308

[1898-6] Gino Fano, Ueber Gruppen, inbesondere kontinuierliche Gruppen von Cremona-Transformationen, der
Ebene und des Raumes, in Verhandlungen des ersten internationalen Mathematiker Kongresses (Zuerich 1897) Teubner Leipzig (1898) 251-255

1899

[1899-1] *Gino Fano, Sulle equazioni differenziali lineari che appartengono alla stessa specie delle loro aggiunte, Atti R. Acc. Sci. Torino 34 (1899) 388-409

[1899-2] * Gino Fano Sulle equazioni differenziali lineari del $V$ ordine le cui curve sono contenute in varietà algebriche Rendiconti R. Ist. Lombardo Sci. e Lett., 32 (1899) 843-866

[1899-3] * Gino Fano, Sulle equazioni differenziali lineari del $V$ ordine e del VI ordine, le cui curve integrali sono contenute in una quadrica, Atti R. Acc. Sci. Torino 34 (1899) 415-445

[1899-4] Gino Fano, Einfuehrung in die Grundlagen del Geometrieby W. Killing, Bollettino di Bibliografia e Storia delle Scienze Matematiche 2 (1899) 14-21 (book review)

[1899-5] * Gino Fano, Osservazioni sopra alcune equazioni differenziali lineari, Rendiconti Acc. Naz. Lincei 81 (1899) 285-229

[1899-6] * Un teorema sulle varietá algebriche a tre dimensioni con infinite trasformazioni proiettive in sé, Rendiconti Acc. Naz. Lincei 81 (1899) 562-565

1900

[1900-1] Gino Fano, Ueber lineare homogene Differentialgleichungen mit algebraischen Relationen zwischen den Fundamentalloesungen, Math. Annalen 53 (1901) 493-590

1901

[1901-1] * Gino Fano, Nuove ricerche sulle congruenze di rette del $3^{\circ}$ ordine prive di linea singolare Atti R. Acc. Sci. Torino 51 (1901) 1-79

[1901-2] * Gino Fano, Sopra alcune particolari congruenze di rette del $3^{\circ}$ ordine, Atti R. Acc. Sci. Torino 36 (1901) 366-379

[1901-3] * Gino Fano, Sui modi di calcolare la torsione di una linea geodetica sopra una superficie qualunque, Atti R. Acc. Peloritana 16 (1901) 198-199

[1901-4] * Gino Fano, Le congruenze di rette del $3^{0}$ ordine composte di tangenti principali di una superficie, Atti R. Acc. Sci. Torino 37 (1901) 501-519

1903

[1903-1] Gino Fano, Lezioni di geometria descrittiva, Torino (1903) (lithographic printig)

1904

[1904-1] * Gino Fano, Sul sistema $\infty^{2}$ di rette contenuto in una varietà cubica generale dello spazio a quattro dimensioni, Atti R. Acc. Sci. Torino 39 (1904) 778-792

[1904-2] * Gino Fano, Ricerche sulla varietà cubica generale dello spazio a quattro dimensioni e sopra i suoi spazi pluritangenti Annali Mat. Pura Appl. 10 (1904) 251-285

[1904-3] * Gino Fano,Sopra una varietà cubica particolare dello spazio a quattro dimensioni, Rendiconti R. Ist. Lombardo 37 (1904) 554-566

[1904-4] * Gino Fano, Sulle superficie algebriche contenute in una varietà cubica dello spazio a quattro dimensioni, Atti R. Acc. Sci. Torino 39 (1904) 597-613

1905

[1905-1] * Gino Fano, Sul sistema $\infty^{3}$ di rette contenuto in una quadrica dello spazio a quattro dimensioni, Giornale di Matematiche 43 (1905) 1-5 
[1905-2] Gino Fano, Un pó di matematica per i non matematici. Geometria descrittiva. Calcolo infinitesimale, Rivista d'Italia 8 (1905) 1-12

$$
1906
$$

[1906-1] * Gino Fano, Sopra alcune superficie del IV ordine rappresentabili sul piano doppio, Rendiconti R. Ist. Lombardo 39 (1906) 1071-1086

1907

[1907-1] Gino Fano Geometria proiettiva, a cura di D. Pastore e E. Ponzano, Torino (1907) (lithograhic printing)

[1907-2] Gino Fano, Gegensatz von synthetischer und analytischer Geometrie in seiner historischen Entwicklung im XIX Jahrhundert, in Enzykl. Math. Wiss. (III) 1 (1907) 221-288

[1907-3] Gino Fano, Kontinuierliche geometriche Gruppen. Die Gruppentheorie als geometrisches Einteilungsprinzip, in Enzykl. Math. Wiss. (III) 1 (1907) 289-388

1908

[1908-1] Gino Fano, La geometria non euclidea, Scientia 26 (1908) 257-282

[1908-2] * Gino Fano, Sopra alcune varietà algebriche a tre dimensioni aventi tutti i generi nulli, Atti R. Acc. Sci. Torino 43 (1908) 973-984

1909

[1909-1] * Gino Fano, Sulle varietà algebriche che sono intersezioni complete di piú forme, Atti R. Acc. Sci. Torino 44 (1909) 633-648

[1909-2] Gino Fano, Lezioni di geometria descrittiva date nel $R$ Politecnico di Torino, Paravia e C. Torino (1909)

1910

[1910-1] * Gino Fano, Sui fondamenti della geometria, Boll. Mathesis 2 (1910) 119-127

[1910-2] * Gino Fano, Superficie algebriche di genere zero e bigenere uno, e loro casi particolari, Rend. Circ. mat. Palermo 29 (1910) 98-118

[1910-3] * Gino Fano, A proposito dell'apparecchio elicoidale per volte oblique, Rendiconti R. Ist. Lombardo Sci. e Lett. 43 (1910) 177-179

[1910-4] Gino Fano, Scuola operaia serale femminile Relazione 1909-1910 Unione femminile Nazionale. Sezione di Torino, Tip. Ditta G. Derossi Torino (1910)

\section{1}

[1911-1] Gino Fano, Matematica esatta e matematica approssimata, Boll. Mathesis 3 (1911) 106-126

1914

[1914-1] Gino Fano, La filosofia contro la scienza, Lettera ad A. Loria, Nuova Antologia (1914)

1915

[1915-1] * Gino Fano, Osservazioni su alcune varietà non razionali aventi tutti i generi nulli, Atti R. Acc. Sci. Torino 50 (1915) 1067-1072.

[1915-2] Gino Fano, Sulle varietà algebriche a tre dimensioni a superficie-sezioni razionali, Annali Mat. Pura Appl. 24 (1915) 49-88.

[1915-3] * Gino Fano, Osservazioni sopra il sistema aggiunto puro di un sistema lineare di curve piane Rendiconti Circ. Mat. Palermo, 40 (1915) 29-32.

[1915-4] Gino Fano, Sui fondamenti della geometria Rivista di Filosofia (1915).
[1915-5] Gino Fano, Il confine del Trentino e le trattative dello scorso aprile con la Monarchia Austro-Ungarica Armani e Stein Roma (1915) 1-10 (conference at Societá di cultura di Torino, June 11, 1915)

1918

[1918-1] * Gino Fano, Sulle varietà algebriche a tre dimensioni a superficie-sezioni razionali, in Scritti matematici offerti ad E. d'Ovidio, Torino (1918) 342-363

1920

[1920-1] * Gino Fano, Superficie del IV ordine con gruppi infiniti discontinui di trasformazioni birazionali, Rendiconti Acc. Naz. Lincei 291 (1920) 408-415. Nota I

[1920-2] * Gino Fano, Superficie del IV ordine con gruppi infiniti discontinui di trasformazioni birazionali, Rendiconti Acc. Naz. Lincei 291 (1920) 485-491. Nota II

[1920-3] * Gino Fano, Superficie del IV ordine con gruppi infiniti discontinui di trasformazioni birazionali, Rendiconti Acc. Naz. Lincei 292 (1920) 113-118. Nota III

[1920-4] * Gino Fano, Superficie del IV ordine con gruppi infiniti discontinui di trasformazioni birazionali, Rendiconti Acc. Naz. Lincei 292 (1920) 175-182. Nota IV

[1920-5] * Gino Fano, Superficie del IV ordine con gruppi infiniti discontinui di trasformazioni birazionali, Rendiconti Acc. Naz. Lincei 292 (1920) 231-236. Nota V

[1920-6] * Gino Fano, A proposito di un articolo del giornale "La Sera", Boll. Mathesis, (1920) 128-131

1921

[1921-1] Gino Fano, Le Scuole di Magistero, Periodico di Matematiche 2 (1922) 102-110

1922

[1922-1] Gino Fano, Sur la congruence des normales à une quadrique, Comptes rendus Ac. Sciences 176 (1922) 1866-1868

1923

[1923-1] Gino Fano, A series of special lectures on Italian Geometry, and 2 general lectures, "Intuition in mathematics" and "All geometry is theory of Relativity", given in the University College of Wales, Aberystwyth, (1923), partial manuscript, Fondo Fano, Mathematical Library of University of Torino

[1923-2] Gino Fano, Vedute matematiche su fenomeni e leggi naturali. Discorso letto nella $R$. Università di Torino per l'inaugurazione dell'anno accademico 1922-23, in Annuario R. Università di Torino 1922-23 Schioppo Torino, (1923) 15-45 (academic year 1922-23's inaugural lecture)

$$
1924
$$

[1924-1] * Gino Fano, Sulle forme binarie per le quali una delle spinte su sé stesse sia identicamente nulla, Giornale di Matematiche 62 (1924) 91-98

[1924-2] * Gino Fano, I gruppi di trasformazioni nella geometria, Scientia 36 (1924) 145-154

[1924-3] * Gino Fano, L'analysis situs I, Scientia 36 (1924) 217-230

[1924-4] * Gino Fano, L'analysis situs II, Scientia 36 (1924) 289-300

[1924-5] Gino Fano, Corrado Segre. Cenno cronologico, Annuario R. Università di Torino 12 (1924)

\section{5}

[1925-1] * Gino Fano, Sulle superficie dello spazio $S_{3}$ a sezioni piane collineari Rend. Acc. Lincei (6) I (1925) 473-477 
1926

[1926-1] * Gino Fano, Sulle superficie di uno spazio qualunque a sezioni piane collineari Mem. Acc. Lincei (6) 2 (1926) 115-129

[1926-2] Gino Fano, Lezioni di geometria analitica e proiettiva, Torino (1926) (lithographic printing)

[1926-3] * Gino Fano, Sulle superficie di uno spazio qualunque a sezioni omografiche, Boll. U.M.I. 5 (1926) 164-167

[1926-4] * Gino Fano, La varietà delle forme binarie del $7^{0}$ ordine a sesta spinta identicamente nulla, Rendiconti Acc. Naz. Lincei 4 (1926) 161-166

[1926-5] Gino Fano, Onoranze a Corrado Segre, discorso commemorativo Suppl. Rend. del Circolo mat. di Palermo XV (1926-1927)

1927

[1927-1] Gino Fano, Intenti, carattere e valore formativo della matematica: conferenza tenuta alla scuola di guerra il 15 marzo 1924 Alere Flammam 7 (1927) 1-26

[1927-2] Gino Fano, Les cycles de la géométrie non euclidienne au point de vue projectif in "In memoriam N.I. Lobatschevskii: Collection des mémoires présentées par les savants de divers pays à la Société physicomathématique de Kazan à l'occasion de la célébration du centenaire de la découverte de la géométrie non-Euclidienne par N.I. Lobatcheffsky (12/24 Février 1926)" volume 2 Glavnauka Kazan (1927) 17-24

1928

[1928-1] * Gino Fano, Un esempio di trasformazione birazionale cubica inerente a un complesso lineare, Rendiconti Acc. Naz. Lincei 9 (1928) 16-19

[1928-2] * Gino Fano, Trasformazioni di contatto birazionali del piano, Rendiconti Acc. Naz. Lincei 8 (1928) 445-451

[1928-3] * Gino Fano, Sulla rappresentazione di S. Lie degli elementi lineari del piano sopra lo spazio punteggiato Rendiconti Acc. Naz. Lincei (1928) 529-534

[1928-4] * Gino Fano, Congruenze $\Omega_{\circ}$ di curve razionali $e$ trasformazioni cremoniane inerenti a un complesso lineare, Rendiconti Acc. Naz. Lincei (1928) 623-627

1930

[1930-1] * Gino Fano, Sulle curve algebriche contenenti serie autoresidue rispetto alla serie canonica, Rendiconti R. Ist. Lombardo Sci. e Lett. 63 (1930) 949-967

[1930-2] * Gino Fano, Sulle sezioni spaziali della varietà grassmanniana delle rette dello spazio a cinque dimensioni,Rendiconti Acc. Naz. Lincei (1930) 329-335

[1930-3] * Gino Fano, Osservazioni sopra una nota del prof. H. E. Baker, Rendiconti R. Ist. Lombardo Sci. e Lett. 65 (1930) 93-96

[1930-4] * Gino Fano, Reti di complessi lineari dello spazio $S^{5}$ aventi una rigata assegnata di rette-centri, Rendiconti Acc. Naz. Lincei II (1930) 227-232

1931

[1931-1] Gino Fano, Spazi di Riemann e geometrie riemanniane. Loro generalizzazioni, Conferenze fis. mat. Univ. e Polit. di Torino (1931-32) 17-60

[1931-2] Gino Fano, Trasformazioni di contatto birazionali del piano, Atti del Congresso Internazionale dei Matematici, Bologna 3-10 Settembre 1928, Zanichelli Bologna (1931) 35-42

[1931-3] * Gino Fano, Sulle varietà algebriche a tre dimensioni aventi tutti i generi nulli, Atti del Congresso In- ternazionale dei Matematici, Bologna 3-10 Settembre 1928, Zanichelli Bologna (1931) 115-121

1932

[1932-1] * Gino Fano, Trasformazioni birazionali sulle varietà algebriche a tre dimensioni di generi nulli, Rendiconti Acc. Naz. Lincei 15 (1932) 3-5

[1932-2] Gino Fano, Geometria proiettiva in Enciclopedia italiana di scienze, lettere ed arti XVI Istituto della Enciclopedia Italiana, Rome (1932) 630-633

[1932-3] Gino Fano, Gl'indirizzi geometrici moderni in relazione ai gruppi di trasformazioni, in Enciclopedia italiana di scienze, lettere ed arti XVI Istituto della Enciclopedia Italiana, Rome (1932) 633-637

[1932-4] Gino Fano, Nuovi metodi e nuovi indirizzi fino a circa la metà del secolo XIX, in Enciclopedia italiana di scienze, lettere ed arti XVI Istituto della Enciclopedia Italiana, Rome (1932) 627-630

1933

[1933-1] Gino Fano, Prof Enrico d'Ovidio, Annuario della R. Università di Torino 9 (1933)

1934

[1934-1] Gino Fano, Enrico d'Ovidio, Boll. U.M.I. 12 (1934) $153-156$

[1934-2] Gino Fano, Scorrendo il volume di F. Klein: Vorlesungen ueber die Entwicklung der Mathematik im XIX Jahrhundert, Conferenze fis. mat. Univ. Polit. Torino (1934) 151-171

1935

[1935-1] Gino Fano A proposito della nota del prof. Majorana: Sull'insegnamento della fisica in Italia, Nuovo Cimento, anno 12 (1935) 49-51

[1935-2] Gino Fano, Geometria non euclidea (Introduzione geometrica alla teoria della relatività) Zanichelli Bologna (1935)

[1935-3] Gino Fano, Complementi di geometria, G.U.F. Torino (1935) (lithographic printing)

1936

[1936-1] * Gino Fano, Superficie algebriche e varietà a tre dimensioni a curve-sezioni canoniche, Rendiconti Acc. Naz. Lincei 23 (1936) 813-818

[1936-2] * Gino Fano, Su alcune varietà algebriche a tre dimensioni aventi curve sezioni canoniche, in Scritti mat. offerti a L. Berzolari, Istituto Mat. R. Univ. Pavia (1936) 329-349

[1936-3] * Gino Fano, A proposito di un lavoro del sig. Ramamurti (Sulle rigate razionali normali), Atti R. Acc. Sci. Torino 71 (1936) 105-109

[1936-4] * Gino Fano, Osservazioni su alcune "geometrie finite” I, Rendiconti Acc. Naz. Lincei 26 (1936) 55-60

[1936-5] * Gino Fano, Osservazioni su alcune "geometrie finite” II, Rendiconti Acc. Naz. Lincei 26 (1936) 129-134

1937

[1937-1] * Gino Fano, Sulle varietà algebriche a tre dimensioni a curve-sezioni canoniche, Mem. Acc. It. 8 (1937) 23-64

[1937-2] * Gino Fano, Sulle varietà algebriche a tre dimensioni a curve sezioni canoniche, Atti I Congr. U.M.I. Firenze (1937) 245-250 
1938

[1938-1] * Gino Fano, Sulle varietà algebriche a tre dimensioni le cui sezioni iperpiane sono superficie di genere zero e bigenere uno, Mem. Soc. It. d. Scienze (3) 24 (1938) 41-66

[1938-2] Gino Fano, Geometrie non euclidee $e$ non archimedee, in Enciclopedia delle Matematiche elementari vol. II-2 Hoepli Milano (1938) 435-511

1940

[1940-1] Gino Fano, Quelques remarques à propos d'une note de M. Amin Yasin Comptes Rendus Acad. Sciences 210 (1940) 284-285

[1940-2] * Gino Fano, Sulle curve ovunque tangenti a una quintica piana generale, Comment. Math. Helv. 12 (1940) 172-190

[1940-3] * Gino Fano, Su alcune particolari reti di quadriche dello spazio ordinario, Revista Univ. Nac. Tucumán 1 (1940) 271-281

[1940-4] Gino Fano, A. Terracini, Lezioni di geometria analitica e proiettiva, Paravia, Torino (1940)

1941

[1941-1] * Gino Fano, Sui cerchi ortogonali a due cerchi dati, Revista Univ. Nac. Tucumán 2 (1941) 87-94

1942

[1942-1] * Gino Fano, Osservazioni sulla rappresentazione di corrispondenze birazionali tra varietà algebriche Comment. Math. Helv. 14 (1942) 193-201

[1942-2] * Gino Fano Su alcune varietà algebriche a tre dimensioni razionali, e aventi curve-sezioni canoniche, Comment. Math. Helv. 14 (1942) 202-211

1943

[1943-1] * Gino Fano, Sulle forme cubiche dello spazio a cinque dimensioni contenenti rigate razionali del $4^{\circ}$ ordine Comment. Math. Helv. 15 (1943) 71-80

[1943-2] * Gino Fano, Superficie del IV ordine contenenti una rete di curve di genere 2, Comment. Pont. Acad. Sci. 7 (1943) 185-205

1944

[1944-1] * Gino Fano, Alcune questioni sulla forma cubica dello spazio a cinque dimensioni, Comment. Math. Helv. 16 (1944) 274-283
[1944-2] * Gino Fano, Osservazioni varie sulle sulle superficie regolari di genere zero e bigenere uno, Revista Univ. Nac. Tucumán 4 (1944) 69-79

1945

[1945-1] * Gino Fano, Nuove ricerche sulle varietà algebriche a tre dimensioni a curve-sezioni canoniche Acta Pontif. Acad. Scient. 9 (1945) 163-167

1946

[1946-1] * Gino Fano, Sulla forma cubica generale dello spazio a 4 dimensioni Rend. Acc. Lincei 1 (1946) 463-466

[1947-1] * Gino Fano, Le trasformazioni di contatto birazionali del piano Comment. Math. Helv. 20 (1947) 181-215

[1947-2] * Gino Fano, Su alcuni lavori di W. L. Edge Rend. Acc. Lincei 3 (1947) 179-185

1948

[1948-1] * Gino Fano, Nuove ricerche sulle varietà algebriche a tre dimensioni a curve-sezioni canoniche, Comment. Pont. Acad. Sci. II (1948) 635-720

1949

[1949-1] * Gino Fano, Su una particolare varietà a tre dimensioni a curve-sezioni canoniche, Rendiconti Acc. Naz. Lincei 6 (1949) 151-156

1950

[1950-1] * Gino Fano, Chiarimenti sopra particolari superficie aventi tutti i generi eguali all'unità Atti Acc. Sci. Torino 84 (1950) 94-96

[1950-2] Gino Fano, Nozioni sommarie di geometria sulle curve e superficie algebriche, Gheroni, Torino (1950) (lithographic print)

[1950-3] * Gino Fano, Irrazionalità della forma cubica generale dello spazio a quattro dimensioni Rend. Sem. Mat. Univ. Polit. Torino 9 (1950) 21-32

1953

[1953-1] Gino Fano, Les surfaces du quatriéme ordre Rend. Sem. Mat. Univ. Polit. Torino 12 (1953-1954) 301-313

[1953-2] Gino Fano, G. Castelnuovo. Commemorazione Atti Acc. Lincei, (1953) (special issue Atti Acc. Naz. Lincei) 